\title{
ADSORPTIVE VOLTAMMETRIC STRIPPING ANALYSIS OF ULTRA-TRACE AMOUNTS OF TIN IN NATURAL WATERS AND SEDIMENTS
}

\author{
SAMUEL B. ADELOJU \\ Electrochemical and Corrosion Technology Research Group, Department of Chemistry, \\ University of Western Sydney, Nepean, P.O. Box 10, Kingswood, NSW 2747, Australia
}

\begin{abstract}
A voltammetric method based on the adsorption of tin(IV)-catechol complex on a hanging mercury drop electrode is described for the determination of ultra-trace amounts of tin in environmental samples. The interfacial accumulation of the analyte and the use of differential pulse voltammetry during the reduction step provide substantial gains in the sensitivity and permit selective determination of tin in the presence of other elements. Optimal conditions for this method are $\mathrm{pH} 4.2,1 \times 10^{-4} \mathrm{M}$ catechol, and accumulation with stirring at $0.0 \mathrm{~V}$ versus $\mathrm{Ag} / \mathrm{AgCl}$. The detection limit based on the use of the tin peak which occurred at $-0.3 \mathrm{~V}$ versus $\mathrm{Ag} / \mathrm{AgCl}$ was $5 \mathrm{ng} / \mathrm{L}$ for an accumulation period of 180 s and the relative standard deviation at $50 \mathrm{ng} / \mathrm{L}$ was $2.2 \%$. The successful application of the method to tin determination in water and sediment samples is reported.
\end{abstract}

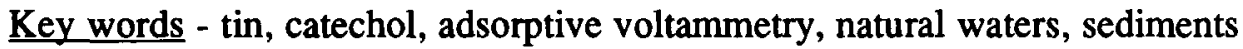

Tin is one of the few elements that are known to be essential at trace levels to man, animals, and plants for a range of metabolic processes $[1,2]$. However concern about its toxicity has been growing in recent times owing to its widespread use in various organic forms for wood preservation, in food packaging, as stabiliser for poly(vinyl chloride), as fungicides or pesticides, as catalysts, in veterinary formulations, and as antifouling agents [3, 4]. As viable antifouling agents, the organotin compounds function by releasing poisonous chemicals to the marine organisms at a slow but steady rate, thereby preventing their attachment to the ship's hull. The released organotin compounds may be ultimately degraded by the progressive removal of the organic groups as follows [4]:

$$
\mathrm{R}_{4} \mathrm{Sn} \longrightarrow \mathrm{R}_{3} \mathrm{SnX} \longrightarrow \mathrm{R}_{2} \mathrm{SnX} \mathrm{X}_{2} \longrightarrow \mathrm{RSnX}_{3} \longrightarrow \mathrm{SnX} \text { where } \mathrm{X}=\mathrm{Cl}^{-}, \mathrm{I}^{-}, \mathrm{Br} \text {, etc. }
$$

Although the amount of the organotin released to the marine environment by the use of antifouling coatings may seem insignificant, their growing use may result in more serious environmental and toxicological problems. Consequently, this has led to the development of numerous analytical methods for the determination of tin in various environmental materials. Among these are various electroanalytical techniques such as dc polarography, ac polarography, differential pulse polarography, and variants of anodic stripping voltammetry. Of these, the anodic stripping voltammetric techniques are suited for the determination of trace amounts of tin because of the added preconcentration of the analyte on the working electrode.

A major difficulty in the determination of tin by anodic stripping voltammetry and polarography is caused by the interference of lead, which often results in an overlap of the tin response [5-10]. The perfect superimposition of the lead response on that of tin in most electrolytes is generally known to result in serious positive errors. Several schemes have therefore been proposed for overcoming the lead interference in the anodic stripping voltammetric or polarographic determination of tin. Most of these schemes are somewhat cumbersome, tedious, and time consuming, requiring scrupulous treatments or chemical manipulations. Furthermore, in spite of the ability to overcome the lead interference by some of these schemes, the achievable detection limits of the order of $1 \mu \mathrm{g} / \mathrm{L}$ is inadequate for the direct and rapid determination of the ultratrace concentrations of tin in unpolluted natural waters. 
The present work describes the use of an adsorption process in overcoming the lead interferences, and enhancing the sensitivity and detection limit for tin. This involves the use of catechol as the sensitising or complexing agent, and the interfacial accumulation of the element as tin(IV)-catechol complex. Factors influencing the reliable utilisation of this approach for the determination of tin such as the $\mathrm{pH}$, concentration of the complexing agent, accumulation potential, presence of inorganic and organic interferences are discussed. The application of the method to the determination of tin in natural waters and sediments is reported.

\section{EXPERIMENTAL}

\section{Reagents}

The acetic acid used in this study was of Aristar grade purity (BDH Chemicals), while other reagents were of analytical reagent grade. Distilled deionised water was used for all solution preparations. Supporting electrolyte was $0.1 \mathrm{M}$ acetate buffer $(\mathrm{pH} 4.2)$. Catechol $(0.1 \mathrm{M})$ was freshly prepared daily in distilled deionised water and kept in the dark to avoid rapid decomposition. Stock solution $(1 \mathrm{~g} / \mathrm{L})$ of tin(IV) was prepared by dissolving stannic chloride in $1 \mathrm{M}$ hydrochloric acid. The required daily standard $(1 \mathrm{mg} / \mathrm{L})$ was prepared weekly by dilution of the stock with $1 \mathrm{M}$ hydrochloric acid.

\section{Instrumentation and glassware}

An EG \& G Princeton Applied Research microprocessor-based polarographic analyser (PAR Model 384), equipped with a PAR Model 303 static mercury drop electrode system and a PAR Model 305 stirrer, was used to record all stripping voltammograms. All glassware and polyethylene bottles were soaked in $2 \mathrm{M}$ nitric acid for at least seven days, washed three times with distilled deionised water, soaked in distilled deionised water, and finally soaked in $1 \mathrm{M}$ hydrochloric acid until ready for use.

\section{Procedure}

A $5 \mathrm{~mL}$ aliquot of the supporting electrolyte or the buffered sample solution containing $1 \times 10^{-4} \mathrm{M}$ of catechol was transferred into the polarographic cell, deoxygenated with nitrogen for $5 \mathrm{~min}$ and maintained under a flow of nitrogen during the experiment. The tin determination was then made by adsorptive cathodic stripping voltammetry at the HMDE using the following conditions: operating mode, differential pulse; accumulation potential, $0.00 \mathrm{~V}$; final potential, $-0.60 \mathrm{~V}$ (versus $\mathrm{Ag} / \mathrm{AgCl}$ with saturated $\mathrm{KCl}$ in both cases); scan rate, $4 \mathrm{mVs}^{-1}$; duration between pulses, $0.5 \mathrm{~s}$; modulation amplitude, $50 \mathrm{mV}$; accumulation time, $45 \mathrm{~s}$ (stirred); and equilibration period, $15 \mathrm{~s}$ (unstirred). The interfacial accumulation of tin on to the mercury electrode was achieved using a fast stirring rate and a medium-sized drop with a surface area of $0.015 \mathrm{~cm}^{2}$. The concentrations of the element in samples were determined by the standard additions method using the peak which appeared at about $-0.3 \mathrm{~V}$ versus $\mathrm{Ag} / \mathrm{AgCl}$ (saturated $\mathrm{KCl}$ ). The solution was deoxygenated after each addition for 30 s prior to the voltammetric measurement.

\section{RESULTS AND DISCUSSION}

\section{Complexation of tin by catechol}

The development and utilisation of adsorptive stripping voltammetry relies on the addition of a suitable and specific chelating or complexing agent which can form an adsorbable complex with the desired element. In order to ascertain the extent of complexation of tin(IV) by catechol, spectrophotometric measurements were made in the acetate buffer solution. Under this condition, the complexing agent formed a water-soluble, red colour complex with tin(IV). This is consistent with the observations of other workers $[11,12]$. The spectrophotometric measurement of the complexing agent alone revealed an absorption maximum at a wavelength of about $450 \mathrm{~nm}$. On addition of tin(IV) into the solution, the height of the initial absorption maximum decreased and an additional absorption maximum was observed at a wavelength of about 550nm, confirming the formation of tin(IV)-catechol complex. The spectrophotometric evaluation based on Job's method, revealed also that the dominant species consist of two catechol to one tin. Evidently, the catechol complexes with the tin(IV) in acetate buffer solution to form a 
dominant tin complex, $\mathrm{SnCat}_{2}$ or $\mathrm{SnL}_{2}$. In effect, this provides a first evidence that the use of catechol may be suitable for sensitising the voltammetric response of tin, provided the complex can be adsorbed on the hanging mercury drop electrode.

\section{Sensitisation of the electrochemical reduction of tin}

Fig. 1 illustrates the influence of catechol on the electrochemical reduction of tin(IV) on a hanging mercury drop electrode in acetate buffer. No distinct response was evident for the reduction of tin(IV) in the absence of the complexing agent. However, the addition of as little as $1 \times 10^{-5} \mathrm{M}$ of catechol resulted in two well resolved stripping peaks which are associated with the established two-step reduction process [5-10]:

$$
\begin{aligned}
& \mathrm{Sn}^{4+}+2 \mathrm{e}^{-} \longrightarrow \mathrm{Sn}^{2+} \quad(\text { peak } 1) \\
& \mathrm{Sn}^{2+}+2 \mathrm{e}^{-} \longrightarrow \mathrm{Sn}^{\circ} \quad(\text { peak 2) }
\end{aligned}
$$

Evidently, the first more sensitive peak which occurred at about $-0.3 \mathrm{~V}$ versus $\mathrm{Ag} / \mathrm{AgCl}$ was significantly influenced by the addition of catechol, possibly due to the formation of the tin(IV)catechol complex, $\mathrm{SnCat}_{2}$, as established from the spectrophotometric measurement. It appeared that the second less sensitive peak which occurred at about $-0.4 \mathrm{~V}$ versus $\mathrm{Ag} / \mathrm{AgCl}$ was not influenced directly by the addition of the catechol, but perhaps indirectly through the sensitisation of the first electrode process. This view is supported by the fact that the second peak did not appear at the lower concentrations $(<2 \mu \mathrm{g} / \mathrm{L})$. It is further interesting to note that the addition of catechol to a solution containing tin(II) gave two similar electrode response. This appeared to be due to the oxidation of the tin(II) to tin(IV). Some workers have already established that tin(II) is rapidly and quantitatively oxidised to tin(IV) by atmospheric oxidation in the presence of catechol $[11,12]$. The main implication of this observation is that the adsorptive voltammetric measurement, based on the formation of tin(IV)-catechol complex, can only be used for the determination of the total tin concentration, unless the tin(II) can be adequately stabilised to prevent oxidation and, hence, enable speciation by this method. Nevertheless, it can be concluded that the distinct role of catechol in the reduction of tin(IV), as evident in Fig. 1, was the promotion of the interfacial accumulation of the adsorbable tin(IV)-catechol complex, $\mathrm{SnCat}_{2}$. Quite clearly the first peak is quantitatively more useful for the reliable and sensitive determination of tin than the second peak.

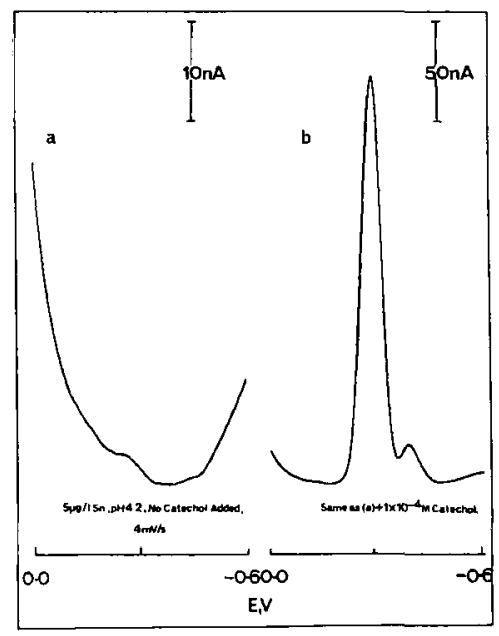

Fig. 1 Influence of catechol on the voltammetric reduction of tin(IV). (a) no catechol added; (b) $+1 \times 10^{-4} \mathrm{M}$ catechol; $5 \mu \mathrm{g} / \mathrm{L} \mathrm{Sn}(\mathrm{IV}) ; \mathrm{pH} 4.2 ; \mathrm{t}_{\mathrm{a}}=60 \mathrm{~s} ; 4 \mathrm{mV} / \mathrm{s}$.

Other factors which influenced the extent of the sensitisation of the reduction of tin(IV) include $\mathrm{pH}$, catechol concentration, accumulation potential and accumulation time. The optimum $\mathrm{pH}$ with respect to the first tin peak was $\mathrm{pH} 4.2$. In contrast, the second tin peak showed only a slight $\mathrm{pH}$ dependence. Also the first tin peak showed a strong dependence on the catechol concentration up 
to $1 \times 10^{-4} \mathrm{M}$, and then only increased slightly up to $5 \times 10^{-4} \mathrm{M}$. Evidently the addition of $1 \times 10^{-4} \mathrm{M}$ catechol is sufficient for the reliable and sensitive determination of the element by adsorptive cathodic stripping voltammetry. In contrast, the second tin peak did not demonstrate an adsorptive behaviour.

The chosen accumulation potential, $\mathrm{E}_{\mathrm{a}}$, also had some effects on the sensitivity of the first tin peak. The optimum $\mathrm{E}_{\mathrm{a}}$ for the first peak lie between 0.00 and $-0.05 \mathrm{~V}$ versus $\mathrm{Ag} / \mathrm{AgCl}$ (saturated $\mathrm{KCl}$ ), where the response was most sensitive. In contrast, the second tin peak remained constant throughout the variation of the accumulation potential. Also as expected for processes limited by the adsorption of the analyte, deviation from linearity is evident even with short accumulation times for the higher tin concentrations. At typical accumulation times $(60 \mathrm{~s}$ for $10 \mu \mathrm{g} / \mathrm{L}$ and $240 \mathrm{~s}$ for $1 \mu \mathrm{g} / \mathrm{L})$, the magnitude of the first tin peak current enhancement relative to the direct measurement (with no accumulation period) are 5 and 16 times, respectively. These data indicate clearly that the rate of adsorption of the tin(IV)-catechol complex is considerably faster when stirring is employed for the accumulation of the metal chelate.

Although the sensitivity of the first tin peak increased considerably with the increasing accumulation times, wider linear concentration range were obtained with little or no initial accumulation. The influence of the various accumulation times on sensitivity, detection limit, and linear concentration range is summarised in Table 1. Generally, lower limits of detection were accomplished with longer accumulation times, but the linear concentration range becomes wider with the decreasing accumulation times.

TABLE 1. The influence of accumulation time on the sensitivity, detection limit, and linear concentration range for tin.

\begin{tabular}{ccccc}
\hline $\begin{array}{c}\text { Accum. } \\
\text { Time } \\
\mathrm{t}_{\mathrm{a}}, \mathrm{s}\end{array}$ & $\begin{array}{c}\text { Sensitivity }^{\mathrm{a}}{\mathrm{nA} / \mu \mathrm{gL}^{-1}}^{-1} \\
0\end{array}$ & $\begin{array}{c}\text { Detection } \\
\text { Limit }^{\mathrm{b}} \\
\mu \mathrm{g} / \mathrm{L}\end{array}$ & $\begin{array}{c}\text { Linear Conc. } \\
\text { Range } \\
\mu \mathrm{g} / \mathrm{L}\end{array}$ & $\begin{array}{c}\text { Correl. } \\
\text { Coeff. }\end{array}$ \\
\hline 30 & 27 & 0.1 & $0-5$ & 0.996 \\
60 & 54 & 0.03 & $0-3.5$ & 0.996 \\
120 & 93 & 0.01 & $0-3$ & 0.999 \\
180 & 117 & 0.008 & $0-2$ & 0.998 \\
\hline
\end{tabular}

a Based on the first tin peak current.

${ }^{b}$ Defined as the quantity of tin which gave a signal to noise ratio of 3 .

[Catechol] $=1 \times 10^{-4} \mathrm{M}$; other conditions as specified in text.

\section{Inorganic and organic interferences}

The presence of other metal ions capable of either forming metal chelates with catechol or depositing into/onto the mercury electrode at the chosen accumulation potential interfered with the determination of tin by the adsorptive cathodic stripping voltammetry. Significant depression of the first tin peak occurred when varying concentrations of other metal ions were added. The least interference was observed in the presence of iron(III), cobalt(II), and nickel(II) ions, at concentrations $<10 \mu \mathrm{g} / \mathrm{L}$, while the most significant depression was observed in the presence of aluminium(III) and copper(II) ions. The addition of $50 \mu \mathrm{g} / \mathrm{L}$ of each of the interferants resulted in more pronounced suppression of between 46 and 74\%, the least being for nickel(II) ions at $46 \%$ and the highest being for aluminium(III) at $74 \%$. In all cases, only the addition of $>10 \mu \mathrm{g} / \mathrm{L}$ cadmium(II) produced an additional peak at $-0.53 \mathrm{~V}$, which may be associated with the reduction of the cadmium(II)-catechol complex. This peak is well separated from the second tin peak by about $-0.13 \mathrm{~V}$ and, therefore, did not affect the resolution of the tin peaks.

Similarly, the presence of dissolved organic substances such as EDTA and Triton X-100 interfered with the tin peaks, either by competitive complexation and masking or by a competition between the organic substance and the metal chelate for the available sites on the electrode surface. In general, the presence of increasing amounts of these substances resulted in greater peak suppression. For example, the first tin peak for $5 \mu \mathrm{g} / \mathrm{L} \mathrm{Sn}(\mathrm{IV})$ was unaffected by the 
presence of $10 \mu \mathrm{g} / \mathrm{L}$ Triton X-100, but was depressed by $25 \%$ with the addition of $100 \mu \mathrm{g} / \mathrm{L}$. Similarly low concentrations of EDTA had no effect, but depressed the peak at higher concentrations $\left(>10^{-6} \mathrm{M}\right)$. Consequently, the standard additions procedure was employed for the quantification of tin natural waters and sediment samples, as a means of compensating for the organic and inorganic interferants.

Replicate analyses of ten separate portions of a lake sediment sample for the ammonium acetate extractable tin based on quantification by standard additions gave a mean tin concentration of $66.00 \mathrm{ng} . \mathrm{g}^{-1}$ with a standard deviation $1.2 \mathrm{ng} . \mathrm{g}^{-1}$. This result compares favourably with the value of $69.2 \pm 3.0 \mathrm{ng}^{-1} \mathrm{~g}^{-1}$ obtained by atomic absorption spectrometry with hydride generation. Other results obtained for samples such as seawater and river water samples further confirmed that the method can be used directly with the standard additions procedure for the reliable determination of tin. The presence of small residual soluble organics in the $\mathrm{NH}_{4} \mathrm{OAc}$ extract did not have any significant effect on the reliable determination of tin in the sediment or water samples. The use of UV-irradiation to remove the soluble organics only marginally improved the sensitivity. Hence, unless a considerably high concentration of dissolved organic substances is present in a sample, there is no need for the ultra-violet irradiation or acid decomposition, as usually recommended for other methods.

\section{CONCLUSION}

The differential pulse adsorption voltammetric method described in this paper provides an effective means for the determination of ultra-trace amounts of tin in natural waters and sediments. The adsorption approach results in the substantial lowering of the detection limit compared to the previously reported electroanalytical methods for tin. Under the established optimal conditions, as little as $5 \mathrm{ng} / \mathrm{L}$ can be reliably determined with only three minutes accumulation time. The precision of the method for natural waters and sediments was also satisfactory with a relative standard deviation of $<2.2 \%$.

\section{REFERENCES}

1. E.J. Underwood, Trace Elements in Human and Animal Nutrition, 4th ed., Academic Press, New York, 1977.

2. D. Purves, Trace Element Contamination of the Environments, Elsevier Science Publishers B.V., Netherlands, 1985.

3. R.J. Maguire, Y.K. Chau, G.A. Bengert, E.J. Hale, P.T. Wong and O. Kramar, Environ. Sci. Technol., 16, 698 (1982).

4. J.S. Han and J.H. Weber, Anal. Chem., 60, 316 (1988).

5. W.F. Condliffe and A.J.H. Skrimshire, J. Polargo. Sc., 1,10 (1961).

6. R.C. Rooney, Analyst, 88, 959 (1963).

7. T.M. Florence and Y.J. Farrar, J. Electroanal. Chem., 51, 191 (1974).

8. T.V. Nghi and F. Vydra, J. Electroanal. Chem., 71, 333 (1976).

9. S. Glodovoski and Z. Kublik, Anal. Chim. Acta, 104, 55 (1979).

10. E. Desimoni, F. Palmisana and L. Sabbatini, Anal. Chem., 52, 1889 (1980).

11. E.J. Newman and P.D. Jones, Analyst, 91, 406 (1966).

12. J.H. Mendez, B.M. Cordero, R.C. Martinez and L.G. Davila, Microchem. J., 35, 288 (1987). 